\title{
Erythrocyte Inclusion Bodies Measurement
}

National Cancer Institute

\section{Source}

National Cancer Institute. Erythrocyte Inclusion Bodies Measurement. NCI Thesaurus. Code C161375.

The determination of the amount of erythrocyte inclusion bodies present in a sample. 